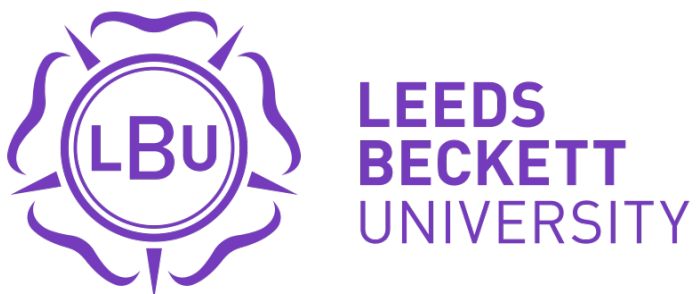

Citation:

Gledhill, A and Harwood, C (2014) Developmental experiences of elite female youth soccer players. International Journal of Sport and Exercise Psychology, 12 (2). 150 - 165. ISSN 1612-197X DOI: https://doi.org/10.1080/1612197X.2014.880259

Link to Leeds Beckett Repository record:

https://eprints.leedsbeckett.ac.uk/id/eprint/256/

Document Version:

Article (Accepted Version)

The aim of the Leeds Beckett Repository is to provide open access to our research, as required by funder policies and permitted by publishers and copyright law.

The Leeds Beckett repository holds a wide range of publications, each of which has been checked for copyright and the relevant embargo period has been applied by the Research Services team.

We operate on a standard take-down policy. If you are the author or publisher of an output and you would like it removed from the repository, please contact us and we will investigate on a case-by-case basis.

Each thesis in the repository has been cleared where necessary by the author for third party copyright. If you would like a thesis to be removed from the repository or believe there is an issue with copyright, please contact us on openaccess@leedsbeckett.ac.uk and we will investigate on a case-by-case basis. 


\section{Developmental Experiences of Elite Female Youth Soccer Players}

2 Adam Gledhill $^{1} \&$ Chris Harwood ${ }^{2}$

$3{ }^{1}$ Sport and Public Services, York College, York, YO23 2BB, UK

$4 \quad$ Tel: +44 (0)1904 770360 e-mail: agledhill@ yorkcollege.ac.uk

$5{ }^{2}$ School of Sport, Exercise, and Health Sciences, Loughborough University,

6 Loughborough, Leicestershire, LE11 3TU, UK

7 Tel +44 (0)1509 226342, e-mail C.G.Harwood@lboro.ac.uk

8

9 For correspondence: Adam Gledhill Sport and Public Services, York College, York, YO23

10 2BB, UK. (e-mail: agledhill@yorkcollege.ac.uk)

11

12

13

14

15

16

17

18

19

20 
2 To advance the literature on talent development within elite female athletes, this study

3 investigated the developmental experiences of elite youth female football players. We

4 adopted an interpretive approach where four players $(M$ age $=16.75)$ were initially

5 interviewed to gain a retrospective understanding of their development as football

6 players. Subsequent fieldwork and further interviews were used to gain a current and

7 prospective understanding of their development as players. Data were subjected to an

8 inductive analysis, composite sequence analysis and a collaborative member checking

9 process to co-construct a sequential, developmental understanding of the players'

10 experiences within elite youth football. The findings suggested that the football

11 experience of fathers and / or older brothers played a significant role in the players'

12 development. Football fathers were able to provide advice and guidance specific to the

13 needs of their daughter-player at different age ranges whilst at the same time reinforcing

14 the importance of coach-player relationships. Football brothers acted as either positive

15 or negative models for their sister-players and served as a source of information about

16 key career choices. Friends inside (termed football friends) and outside (termed non-

17 football friends) football played a significant role in helping players to lead the

18 disciplined lifestyle required of an elite youth football player. Finally, findings suggest

19 that self-regulation and adaptive volitional behaviours appear to be key intra-individual

20 factors associated with talent development in female football. These findings are

21 considered in the light of previous talent development literature alongside directions for

22 future research.

23 Keywords: elite youth female soccer; talent development; composite sequence

24 analysis 
1 For females, the growth of football participation worldwide has been dramatic over the

2 past ten years with football now the number one participation sport for females in a

3 number of countries including England, Norway and the USA (Hong, 2003).

4 Worldwide, there are now 2.9 million registered youth female players, equating to a

$532 \%$ increase since 2000. With the success of the recent UEFA Women's European

6 Championships in 2009 and the FIFA Women's World Cup in 2011, women's football

7 is now in a unique position where its' profile can be raised on an international level.

8 This undoubtedly offers the opportunity for the development on a global scale.

The growth of female football has led to an increased focus on female player

10 development within different countries. In England, for example, the Football

11 Association's (FA) 'Women's and Girl's Football Strategy 2008 - 2012' focuses on the

12 development of female football at all levels of participation and at different levels of

13 involvement (e.g. players, coaches and officials). Within their strategy, the FA state that

14 there is a need to develop better female players, increase and retain female participation,

15 raise standards and behaviour, and increase awareness and positive perception of the

16 women's and girls' game. Unfortunately, within talent development in general, there is

17 a lack of widespread evidence - based practice (Bailey et al. 2009) and the translation

18 of sport science research to practice has generally been found wanting (Bishop, 2008;

19 Ford, Yates \& Williams, 2010).

Whilst there has been sociological debate about the development of female

21 football on a worldwide scale (e.g. Hong, 2003) that demonstrated an appreciation of

22 the growth and importance of female football, there remains a lack of research with

23 youth female football players that has that has targeted an understanding of their

24 developmental experiences from a longitudinal perspective (Gledhill \& Harwood, 2011;

25 Van Yperen, 2009). This has particular importance for two key reasons. First, child, 
1 adolescent and adult experiences are quantitatively and qualitatively different (Wiese-

2 Bjornstal, LaVoi \& Omli, 2009). This suggests that to understand the experience of a

3 female youth player, researchers must examine this experience from their perspective.

4 Further, because only a minority of talented young female football players can progress

5 onto being elite level adult players, our understanding of such developmental

6 experiences could play a vital role in helping football organisations to enhance the

7 female game by learning from those who have lived that experience. Second, in sport

8 psychology research in general, male athletes are disproportionately represented when

9 considered alongside female players, suggesting a greater depth of investigation with

10 female players is required (Conroy, Kaye \& Schantz, 2008). Given the male-dominated

11 structure of professional sport, the needs of females athletes are often misunderstood

12 (Douglas \& Carless, 2009). Many of the major posits of talent development in football

13 research are based on findings from predominantly male populations (Gledhill \&

14 Harwood, 2011), with conclusions being transposed into female football. This is

15 particularly apparent with the major conceptual framework associated with talent

16 development in football (Holt \& Dunn, 2004) where the key findings are based on the

17 experiences of male youth football players. This makes the generalizability of findings

18 into female football difficult due to developmental differences between males and

19 females (Gill, 2001).

Whilst the body of research into youth sport has undergone recent expansion

21 (e.g. Holt, Black, Tamminen, Fox \& Mandigo, 2008; Holt, Tamminen, Black, Mandigo

22 \& Fox, 2009), still little is known about the developmental experiences of youth football

23 players from the player's perspective. Further research that is sensitive to different

24 stages in the developmental process and with individuals from a range of talent

25 development systems is needed (Holt \& Dunn, 2004). 
2 often explore patterns of development in psychosocial factors affecting sport

3 participation. The term 'development' is seen to refer to the nurturing and enhancement

4 of football players (Holt \& Dunn, 2004). A developmental approach focuses on internal

5 affective and psychological processes which influence social relational interactions

6 whilst also appreciating an individual's progressing maturational phases. Inevitably,

7 throughout a player's developmental process, there will be multiple social agents

8 (Ullrich - French \& Smith, 2009) that act upon the athlete that will influence their

9 development, both as young football players and as young people. Previous football-

10 specific literature has examined social and motivational predictors of sport participation

11 (e.g. Ullrich-French \& Smith, 2009), the influence of coaching behaviours (e.g. Weiss,

12 Amorose \& Wilko, 2009), and parenting styles (e.g. Sapieja, Dunn \& Holt, 2009);

13 however there are few links made specifically to the talent development of elite female

14 football players. In addition, there is currently little understanding from a developmental

15 perspective or relating to if or how their perceived influence changes throughout the

16 course of a female football player's career.

17 Given the lack of literature that adopts a developmental approach, the aim of the

18 current study is to gain a richer insight into the developmental experiences of elite youth

19 female football players by adopting a qualitative approach that is supplemented by a

20 composite sequence analysis. When combined, these approaches can serve to provide a

21 rich developmental understanding of developmental experiences of female youth

22 football players. This is will be achieved by addressing the following key research

23 questions: a) What are the developmental experiences of elite youth female football

24 players; b) How do these experiences change throughout their playing career; c) What

25 are the key factors that players feel have helped them to become an elite youth player; 
1 and d) How do players feel these key factors have influenced their developmental

2 experiences?

\section{Method}

\section{Participants}

5 We used purposive sampling which involved the selection of a sample of female

6 football players $(\mathrm{N}=4 ; M$ age at time of first interview $=16.75$ years, $S D=0.5)$ for

7 whom the research questions were relevant (Patton, 2002). Given the focus of the study,

8 the sampling criteria were that players had to play for a youth international team,

9 international college representative team or a team in the Women's Premier League

10 (WPL - the highest level of female football in the UK at the time of the first interview),

11 thus making them a clear representative sample (cf. Barker et al. 2010). Players reported

12 a mean playing experience of 8.13 years $(S D=0.48)$ which included attaining the

13 following levels of performance: youth international level $(n=3)$, international colleges

14 representative team $(n=4)$ and WPL $(n=4)$. Players represented different club teams and

15 two players transferred club teams (by entering the newly formed Women's Super

16 League) during the study. Access was gained to players through the lead author's

17 professional acquaintances within football. All players were from a divorced-remarried

18 parental structure and lived with their biological mothers and step-fathers. All players

19 and their families were from a white Caucasian background. Each player received a

20 participant information letter and informed consent form that was appropriately

21 completed prior to the study commencing.

\section{Data collection}

23 This study took place over a 20 -month period. We adopted an interpretive qualitative 
1 approach where players were encouraged to provide the lead researcher with 'their

2 story' of their developmental experiences in football. This provided an interpretive form

3 of understanding to gain a rich understanding of their lived experiences. Given the

4 prospective element of the study, the interpretive approach allowed us to study these

5 players' stories as they unfolded over time (Smith, 2010). An important reflection here

6 is that 'data' refers to information gained from all meetings ${ }^{1}$ with players. This data

7 included transcriptions of audio recordings of interviews, information from a reflexive

8 audio diary and field notes made by the lead researcher during, or shortly after,

9 meetings (c.f. Douglas \& Carless, 2009).

\section{$10 \quad$ Interviews}

11 In total, 10 formal interviews (three each with Beth and Lisa pre-season 1, post-season 1

12 and post-season 2; two each with Amanda and Michelle who were unable to attend

13 formal interviews post-season 1) took place over the course of the study (mean duration

$14=52.2$ minutes, $\mathrm{SD}=9.81)$. Interviews were conducted by the lead researcher who has

1515 years' experience coaching football to both male and female players as well as eight

16 years' experience providing sport science support to youth athletes. Data was collected

17 as part of the lead author's $\mathrm{PhD}$ thesis examining psychosocial factors associated with

18 talent development in female football. No players in the current study had previously

19 been coached or supported by either of the researchers conducting the study. The

20 interviews were audio recorded and professionally transcribed. During each interview,

21 clarification probes (Rubin \& Rubin, 2005) were used to clarify meaning and add depth

22 to the understanding of the players' experience (cf. Douglas \& Carless, 2009). During

\footnotetext{
${ }^{1}$ The term 'meeting' refers to formal interviews, attending games, informal face - to - face discussions and telephone conversations.
} 
1 interviews, the lead researcher discriminated between those instances where the order

2 and connections between experiences appeared clearly from the athletes' accounts and

3 those instances where this was less clear (cf. Nieuwenhuys, Vos, Pijpstra \& Bakker,

4 2011) as the quality and clarity of players' expressions potentially influences the

5 sequential structuring of experiences. In instances where the order or sequence of events

6 was unclear, probe questions were further adopted to ensure accurate sequential

7 structuring.

The interview guide was based on a systematic review of football specific

9 literature (Gledhill \& Harwood, 2011) and was separated into the following areas:

10 General background in football / rapport building questions (e.g., How did you get

11 started in football?); family (e.g., Have your family helped you to develop as a player?);

12 peers (e.g., Do your peers influence your development as a player?); coaches (e.g. What

13 do you think are the qualities of a good football coach?), psychological skills use (e.g.,

14 Do you use any particular psychological skills to help develop your football?);

15 perceived football competence (e.g., What do you think makes you a good football

16 player?); and perceived personal qualities (e.g., What personal qualities do you think

17 you possess that have helped you to become a good football player?). The initial

18 retrospective interviews served to allow players to reflect on their career to date to

19 provide their stories in an open - ended manner using their own words (cf. Douglas \&

20 Carless, 2009). Questions were centred on the different age groups that players

21 progressed through within football. The interview guide was provided to players prior

22 to the interview so that they had time to consider the focus and nature of the interview

23 with a view to increasing the richness of data collected (cf. Christensen, 2009). Follow-up interviews served to investigate the current aspects of the players' careers and their development during the course of the study (e.g., Are there any 
1 changes happening in your career now; How do you feel you are currently developing

2 as a player?). The prospective aspect of the interviews pertained to the players' future

3 career development (e.g., what do you think you will need to do to be able to progress

4 from this point? What help / advice do you get from [significant people around you] that

5 helps you to develop as a player? How do you feel this help / advice is contributing to

6 your development?).

\section{$7 \quad$ Fieldwork}

8 Alongside interviews, the lead researcher used informal data collection methods during

9 fieldwork to allow the players to feel more at ease leading to greater rapport

10 development (Pitts \& Miller-Day, 2007), to reduce the influences of recall bias, and to

11 allow for the developmental tracking of players. During the 20 month period, the lead

12 researcher had a number of open ended informal discussions with participants. These

13 discussions included a variety of topics that were raised by the players (e.g., progression

14 between international age groups, breakdown in coach -athlete relationships, changing

15 playing position, team manager resigning). Furthermore, the lead researcher also

16 attended 19 league and youth international football matches in which the players were

17 participating. This yielded further informal pre- and post-match discussions surrounding

18 a range of developmental topics; from pre-match discussions about 'how things were

19 going', to post-match discussions surrounding feedback from coaches or feedback and

20 comments from fathers.

\section{Data analysis}

22 Data was initially analysed using the two stage method of inductive content analysis

23 (Côté, Salmela, Baria, \& Russel, 1993). This method adopted a line by line analysis to

24 provide an initial descriptive understanding of the themes that emerged from the data. 
1 Philosophically, we adopted an interpretive approach whereby the developmental

2 experiences of these players could be interpreted using their words, subjective meanings

3 and representations.

4

\section{Composite sequence analysis (CSA)}

22 The CSA (see figure 1) of events found that between ages 6-10, the brother and father

23 of the developing player were important for initiating play in football. In addition, the

24 father was important for encouraging play in football and peers were important for 
1 facilitating play in football. Between the ages of $10-12$, competition against male

2 counter parts was important for developing football specific attributes. Ages $12-14$

3 offered the female players the opportunity to enter organised female-only football and

4 provided them with the opportunity to "stand out" amongst other female players.

5 However, players also thought that they developed the least in their formal football

6 development during this period. This was related to being no longer allowed to compete

7 against male players in matches, even though they did still play against male players in

8 unsupervised games. Between the ages of $14-17$, involvement in organised female

9 football (consistently with junior squads of WPL teams) was seen as important as this

10 provided the opportunity to stand out against other female players, thus providing

11 opportunity for entry to international level. During these ages, the increased

12 commitment, discipline and sacrificing a "normal teenage life" was central to continued

13 development and 'non - football friends' were important in assisting this process

14 outside football. Between $17-19$ years, further increased commitment was noted

15 through sacrificing elements of what players referred to as a "normal late teens / early

16 adult life" (such as refraining from having a boyfriend / girlfriend, and from drinking

17 alcohol). Players also noted an increased attention to, value of, and actioning of, the

18 technical advice provided by coaches, experienced fathers and experienced brothers.

19 Finally, this was the age range where players began to use different psychological skills

20 (e.g. self-talk, goal-setting, imagery) more frequently. Throughout all age ranges, the

21 father and brother acted as role models, a source of football inspiration and important

22 providers of informational support. Furthermore, emotional and tangible support from

23 family members was viewed as central to continued involvement and development as a

24 player. Enjoyment and perceived competence were important for initiating and

25 continued participation, with perceived competence also being seen as a factor in 
1 improving as a football player. Finally, social support from peers was an important

2 factor in maintaining participation.

\section{$8 \quad$ Football-fathers}

9 A meaningful developmental influence from the earliest age of playing football (6

10 years) and throughout the playing career was each player's biological father (football

11 fathers). Corroborating previous football-specific findings from elite youth male players

12 (e.g., Holt \& Dunn, 2004), the football-father provided tangible support in the form of

The following sections will now elucidate these key developmental themes, using block quotes of the players' voice that convey the meaning of the players' experiences (cf. Barker et al. 2010; Douglas \& Carless, 2009). Pseudonyms are attached to player comments to maintain confidentiality. Integrated are discussions in the context of prior literature, and future research and applied implications. transport and finances. Michelle and Lisa pointed out that their fathers "took them everywhere" to play football, whereas Beth pointed out that her father provided finances for kit, such as buying her new boots. All players highlighted that their fathers watched a lot of their football which they felt was a sign that their fathers were interested in their development and this fostered positive father - child relationships.

To our knowledge, a finding unique to this study was that each football-father had a current or previous role within professional football either as a player, or a coach, or both. Most meaningful from a talent development perspective was that, as a result of their fathers' experiences in football, players had access to high quality informational support. Informational support provides individuals with advice or guidance about possible solutions to problems (Holt \& Dunn, 2004). Each player reported this as significant in their development and told a story about how their father had helped them 
1 to develop as a player. Michelle had an interesting relationship as her father was also

2 her football coach when she was younger. "My dad coached weekends when I was growing up and he took me with him...It was quite nice being coached by my dad as I was growing up. Sometimes you'll get coaches that don't really know how to handle you, but because he was my dad as well, he knew how to handle me. He knew what I wanted from football; he knew how I learnt things best so all that really helped

9 Lisa discussed how she respected her father's playing experience and how his understanding of his daughter helped to contribute to her development as a football 11 player: "...he was always taking me to the park and having a kick about with me and then I found out that he was quite a good player in his day. He was at [professional clubs] but then had to retire because of injury. He knows his stuff to be fair and he is always my worst critic but it's good cos he knows me and knows how I work, so if I've played bad and come off the pitch in a mood, he knows how to deal with me and talks to me about stuff I can do to improve."

After moving to a new club (at the highest level of women's football in England), Beth discussed how her father has helped to develop her and also provides an insight into how her father's behaviour has changed towards her during the more recent stages of

\section{1 her career:}

"My dad is always honest with me about how I'm going. It's really important to me as obviously he knows a lot about football being a former player and now coaching, and for him to talk to me about what I need to do is only going to push me on further. As I've got older the type of advice he gives me has got more 
technical... Now that I'm playing at a higher level, I've learned more about the game and we can now talk much more in - depth about it and it's like me and my dad are talking about how I can improve now rather than my dad just telling me what I've done right or wrong and how I can improve. My dad always like asks me now what the coach has said to me in my reviews too...I know how hard it is going to be to get into the [senior international team], so my dad is always helping me understand what's been said and encouraging me to listen to what my coach has said. It's good with my dad now cos I don't ever get a lie out of him now about football."

This provides an important extension to previous football parenting literature which highlighted that more competent parents of female football players were able to have effective performance-related discussions with their children post competition (Holt \& Black, 2007). As these players' careers progressed, they perceived their fathers to increase the quality of informational support given to match the requirements of the player and players placed great emphasis on this because of the professional experiences of their fathers. In attempt to explain player-level benefits of this, based on the fact that these football fathers were essentially coach-fathers, we examined the sports coaching (e.g. Ford et al., 2010), pedagogy (e.g. Hubball \& Robertson, 2004) and parenting literature. From this, we surmised that these coach-fathers were enhancing the development of their daughter-players by creating an effective learning environment using techniques acquired through their playing experience and / or coach education. Due to the positive father-daughter relationships reported by players we argue that the developmental impact of fathers was greater given the motivational influence that parents exert (Gershgoren, Tenenbaum, Gershgoren \& Eklund, 2011). 
The informational support from the father occasionally differed from the advice

2 that was being provided by the coach. Given the experience and knowledge of the

3 fathers in this study, this sometimes became a source of internal conflict for the players

4 as they were unsure of which advice to follow. Importantly, the football fathers

5 encouraged the players to follow the advice provided by the coaches rather than their

6 own as the advice of the coach would tie in with the needs of the team. For example,

7 during a conversation after a game where Michelle had immediately gone to speak to

8 her father about her performance, I asked Michelle how she felt about her dad speaking

9 to her about her performance after games. She offered the following observations: “As I've got older and moved to [current team] my dad still talks to me about how I can improve cos he still watches all of my games when he isn't coaching. I always take my dad's advice on-board but whenever my dad says something different to my coach, he will always be like 'take your coach's advice because

17 Speculatively, we assume that this parenting style is grounded in the fathers' experience within professional football. We maintain that this football experience has provided

19 these football fathers with a more empathic understanding of the importance of the 20 coach - player relationship (Becker, 2009) and the influence that they (as football 21 parents) could have on the dyadic coach - player relationship (Jowett \& Timson-

22 Katchis, 2005). However this assumption can merely be accepted as informed speculation in the absence of data from these football fathers. In addition, given the positive tone conveyed by players exposed to this paternal football background and 
1 experience, we cannot assume that such facilitative father-daughter dyads will exist

2 where fathers lack such specificity of football knowledge and experience. Notwithstanding this lack of data from parents with differing backgrounds, our

4 results demonstrate important examples of football parenting perceived as facilitative by 5 developing players. Previous soccer-specific literature (e.g., Holt \& Mitchell, 2006) has

6 noted how parents can be a potential obstacle to talent development in football if

7 inappropriate parenting behaviours are adopted. Therefore, the behaviours of the

8 football-fathers in the current study could serve to enhance current parent education

9 literature for other football parents with a view to enhancing player development. A final point of consideration here is that all of the players in the current study

11 were from divorced-remarried parenting structures. Although players were not asked if

12 they felt this had impacted on their development as players, literature investigating the

13 impact of divorce on children has suggested that they can develop and utilise more self-

14 regulation and coping strategies (Mo-Yee, 2002). As self-regulation and coping

15 strategies have been cited in football specific research as distinguishing factors in

16 football success (Holt \& Dunn, 2004; Jonker Eleferink-Gemser \&Visscher, 2010),

17 examining the impact of parental structure on player development in football is a

18 noteworthy future direction.

19 Football-brothers

20 Players in the current study all perceived their siblings as playing significant roles in

21 their development as players. All of the players in the current study had at least one

22 older brother that had played football from county representative squad level to full

23 professional status (a football brother) and was important from the ages of 6-10 in

24 helping them become interested in football. For example, Beth, Lisa and Amanda all

25 reported that their older brother was the first one to invite them to go and have a "kick 
1 about" and they found this initial involvement enjoyable. Lisa also linked in that her

2 brother had helped with her initial socialisation into football which helped her to cope

3 with the nature of football players:

4

"It all started with my brother really. When I was younger, like 9, I used to go out there with my brother and we'd go play with some of the lads from school and their brothers and because of that I started playing in my local boys team at U10. After that I went into the U12 boys' team and then started at current club's junior team]. I just really enjoyed getting out there and playing with them, it gave me a right buzz."

As players got older and had aspirations of elite football, the older brother of the female players had significant modelling effects either as a positive or negative model.

Contrary to previous sibling literature that suggests younger siblings may attempt to deidentify with older siblings (e.g., Sulloway, 1996), it was clear that players viewed their older sibling as a football role model and wanted to emulate (Azmitia \& Messer, 1993) or surpass their brother's achievements. Unlike sibling conflict literature (e.g. Haggan, 2002), this desire to surpass the older sibling did not result in conflict. In fact, players perceived this desire to progress as strengthening the sibling bond. This was due to the older sibling's wish to help their younger sibling to succeed. In order to develop, players received advice about the brother's experiences and learned from these (cf. Azmitia \& Messer, 1993). When invited to talk openly about how her brother had influenced her as a football player, Michelle offered the following observations about the lessons she had learned from her football brother as a negative role model: "He had all the talent in the world and he was at [a professional club] from a really young age but he let it all go to his head. He thought he'd made it when he was 16 when really he should have known that you haven't made until you're 
like...David Beckham. He made lots of wrong choices like not looking after himself, going out drinking with his friends a lot and never really listening to his coach. My brother always thought that he knew better than everyone else. When I saw him get kicked out of [professional club], I saw how he reacted and now he'll advise me on his mistakes and that has helped shape my career"

Beth provided an alternative perspective regarding the positive role model effect of her football brother:

“He was a model pro. You can’t question what he achieved in football. I learnt a lot from him about diet, nutrition and generally looking after yourself... If you don't look after yourself, you'll never make it as a footballer. Because of that, I'm not bothered about going out drinking and stuff and I really try to look after myself."

Amanda provided a different context to the role of the football-brother. She discussed how deliberate play with her older brother had developed her as a player through exposure to position specific requirements and, ultimately, how this impacted on her early career:

"well, he always played right hand side of midfield, so I've ended up playing there too now. We took turns crossing the ball for each other all of the time. I used to be the person he'd aim for but then we'd swap over. Then we'd like act as defenders for each other and we'd race for the ball and stuff, so that was great for me because I'm really small so when I started playing football, I'm not being big headed like, but I was already really fast - I never liked [brother's name] beating me to the ball even though he always did! I was already good at running past people with the ball, could do tricks to get past people and I could cross a 
3 These preliminary findings expand current understanding (e.g. Holt et al., 2009) to

4 demonstrate part of the mechanism by which the older siblings exerted their effect. In

5 addition, findings have added to current sport literature (e.g. Davis \& Meyer, 2008)

6 from same sex siblings by mirroring emotional and informational support related

7 findings in siblings of different sex. However, as all of the players in the study were the

8 youngest child in birth order, the findings do not allow for discussion of birth order

9 effects.

\section{$10 \quad$ Peer experiences}

11 Peers emerged as a positive motivational influence on players in terms of both

maintained involvement in football and as a resource for player development. Extending earlier literature (Ullrich-French \& Smith, 2009), players discussed the notion of football friends (friends that were also team - mates) and non - football friends (friends that were from outside football, such as school friends). In doing so, players differentiated between the relative roles of these distinct groups on talent development. Players received emotional support from football friends, particularly during times of difficulty, such as bullying, injury or being dropped from the team. For example, football friends provided social support that served to change Michelle's perceptions and understanding of female involvement in football and how peers at the age of 12 helped her to recover from being bullied for playing football: "You know, as I was growing up I got bullied quite a lot because I played football. All the lads were like 'ah, you play football, you're a man'...and my first football team basically told my dad that I wasn't going to play because I was a girl, even though we were only 11 so I could play on the same team as the 
7 Whilst similar findings are evident in female physical activity settings (e.g. King,

boys. I was like 'my god, am I the only girl that plays football?' I would say the main people that helped me get past that were my team mates. I got to my new club and it was all girls and it was like 'I'm not the only girl that plays football!' and they had all been through the same thing as me, you know the bullying and stuff, so they were the biggest support for me because they understood it when they'd been through it".

Tergerson \& Wilson, 2008), to our knowledge this is the first finding of its type that has demonstrated how social support has indirectly led to progression to elite level female football.

Between the ages of 12-14, female players participated in deliberate play (Côté, Baker, \& Abernethy, 2003; 2007) against male players as this enhanced their enjoyment of football during a time when they felt a lack of development from playing against female players. Players saw this 'friendly' competition against male players as essential for development particularly because of the increased demands of playing against males and how this helped developed physical strength and perceptual skills (cf. Berry, Abernathy \& Côté, 2008). Although from a small sample of elite youth female football players, the importance placed by female football players on the competition against male players is a pertinent finding in this study as it underscores the importance of tailoring female football to the needs of elite players during the sampling and specialising years. This has contemporary importance in the current structure and organisation of child and youth football in countries where age restrictions for mixedsex competitions are currently in place. For example, in England, recent Football Association rule changes (rule C4 (a) (vii)) stipulate that female and male players can only compete against each other up to U13 level- the female players in this study saw 
1 such limits as disadvantaging their development as players. Other countries in

2 Scandinavia and Central Europe have fewer restrictions which could influence the

3 development of their players.

All of the participants discussed how peers, both football friends and non -

5 football friends, helped them to lead a disciplined lifestyle. These included encouraging

6 players to maintain their disciplined lifestyle and arranging activities that would allow

7 players to socialise without any issues that could negatively affect football. Beth

8 discussed how her friends had contributed to supporting her involvement in football and

9 how this has changed as she has progressed as a footballer: "My friends when I was younger always used to talk to me about football and stuff and like why I played it and things like that and they always seemed quite interested cos they knew I was good at it. When I think back, that was quite important because it made me think about why I played it and what I needed to do to keep playing. As we got older, and they started going out and stuff, they were never like 'oh just miss training and come get drunk with us' so not having that pressure helped me to avoid the temptation, instead they'd like say 'oh, shall we organise a night we can go bowling or go to the pictures when you're not busy with football?', which was important cos sometimes you do sort of like feel that you have to miss out on being a teenager if you're going to be a good football player... As I've gone further up in football, like at youth international on the Women's Super League, some of my friends give me some banter about never seeing me... but that's good for me cos it shows that they still wanna be around me and they still make plans to see me."

24 These findings suggest that non - football friends brought a sense of 'normality' into

25 the teenage lives of the players that helped them to focus on non-football matters. This 
1 fostered a 'time-out' period from football when a rest was needed. In addition, players

2 reported that non - football friends would help them maintain a disciplined lifestyle by

3 changing the plans of the social group to accommodate the player's needs. In one of the

4 later discussions after she had started regularly representing [senior team], when asked

5 about the role of her friends outside football, Michelle offered the following: "My friends realise how important my football is to me so...they're not always like lets go out Friday, Saturday night or whatever, they're always like you go training get yourself sorted out and then we'll arrange a time to go to the cinema or something. They respect that I have to balance my life quite a lot, so they make time for me rather than trying to get me to do the things that I shouldn't really be doing."

These initial findings provide suggestions regarding the differing roles of both footballand non-football peers in talent development and warrants further in - depth qualitative investigation.

\section{Early access to competition}

All players retrospectively reported the importance of early access to competition as an essential part of the developmental experience. Of particular importance to them was playing football against boys up until the age of 12. Below, Beth explains her perception of the experiences:

"Yeah, it was really good playing against boys at that age because it gave me that competitive edge. You know, boys don't want to lose to the girls because boys can't lose to girls, and girls don't want to lose to the boys because they want to prove that they can play football as well so that's where I got my competitive edge and it just grew from there. Playing against boys who were bigger and stronger was better for me cos it developed me physically I think, but 
also because the standard of girls football at that age was never as good as the boys so yeah, I found it really beneficial playing against boys".

As noted by Amanda however, she thought it was important in her development to play with male players in unsupervised games "I was as good as, if not better than a lot of the boys I played against, but the FA said we're not allowed [to carry on playing against boys after the age of 12] ... I just carried on playing against lads outside the organised games because they were so much better than any of the girls I played against."

\section{Coach}

The data presented provided a female youth specific insight into the perceptions of the roles of coaches and understanding player - coach relationships. Fasting and Pfister (2000) reported that elite female players viewed female coaches more positively than male coaches due to a greater understanding of the needs of female players on the part of female coaches. In this study, male coaches were often reported to have unrealistic performance-related expectations. Michelle reported:

"I think there is a big difference between working with male and female coaches. I think male coaches in general treat women's football the same way as they treat men's football and they don't realise that women physically can't do the things that men can sometimes. When I'm coached by women, I find they treat us as women and women footballers rather than expecting us to be men! The male coaches tend to expect us to do things faster because that's what they're used to with men and when we can't they just tell us to do it better or do it faster and my head just goes straight down because you don't know what they expect to you to do." 
1 However, three players preferred working with the male coaches due to greater

2 perceived technical coaching competence. Beth discussed some of the differences she

3 has experienced and how they have affected her development:

4 "It's like, I know technically male and female coaches should be as good as each other as they have to do the same coaching badges and stuff, but I just think that the male coaches that I've worked with are so much better in some ways. Like my coach now, he pays so much attention to detail in everything, he knows each of the different players individually and knows each of our individual needs and because of that we get so much more out of working with him. I've never really had that with a female coach."

Furthermore, some players in the current study did not report the same

communication problems reported by Fasting and Pfister (2000). Beth provides an insight into her experiences:

"I don't really feel comfortable talking to women managers...but with male managers I feel like I can talk about anything. Like with my club manager now, he is always there for me, he always wants the best for me and he will do anything to make sure that his players are happy; I've never really had that with a female manager. At international level, it is harder to form relationships with the manager as well because you don't see them as often and you don't know them as well, so I've always found it easier to form relationships with my club manager."

The positive experiences with male coaches reported in this study could be explained by the positive relationship that female players developed with other significant males in their life (e.g., football fathers, football brothers) and how the players had become accustomed to talking to males about their football performance. However, when the 
1 communication pathway was reversed with the coach providing information to the

2 player, each player reported negative coach interaction due to inappropriate

3 communication styles (cf. Holt, Tamminen, Tink \& Black, 2009). These findings

4 suggest a need for further coach education relating specifically to the needs of female

5 youth football players.

\section{Self-reflection and volitional behaviour}

7 During the course of the study, Beth's career progressed the furthest. She regularly

8 represented a senior team in the highest level of women's football in the UK and

9 amassed the highest number of international caps. Towards the end of the first season,

10 all players were asked what they thought they needed to do to be able to progress in

11 their football career. Interestingly, Amanda, Lisa and Michelle's responses were limited

12 to statements such as "keep working hard and hope I get the call" or "listen to my

13 coaches and see where I can go from there". During one of the fieldwork sessions, Beth

14 provided a response that demonstrated she had volitionally taken a reflective stance on

15 her own football performance and had identified strengths and areas for improvement

16 that she was trying to work on:

17 “...because I really want to move into the senior international team now, I've

18 started watching the senior internationals and the senior players in my team a lot

19 more now to try to figure out what it is they have that I don't. I know it's a team

20 game, but when you want to play for [international team] it's almost like you're

21 competing against your team mates as well. I've noticed that I need to work more

22 on my left foot because [senior international player currently playing in Beth's

23 position] is miles better than me with both feet. My right is really good but when I

24 come inside, I need to be better with my left so that I have a better range of

25 passing." 
1 In addition to reflecting on her football performance, Beth also reported using goal,-

2 setting strategies and psychological skills training techniques (specifically self-talk,

3 affirmations and imagery) as coping strategies and for performance enhancement. As

4 self-reflection and volitional behaviour are key aspects of self-regulation, we considered

5 self-regulation literature to interpret the potential impact of Beth's behaviours.

\section{Implications and Conclusions}

7 The current study has provided an account of the developmental experiences of elite

8 female youth football players and has placed these experiences in a CSA of events

9 bound by age ranges. A key strength of this research has been its ability to highlight

10 links between elite female talent development and positive youth development by

11 suggesting a reciprocal, cyclic link between these two areas, as well as mechanisms

12 behind the link. Specifically, we have illuminated the role of non-football friends in

13 helping developing female players to maintain the disciplined lifestyle required for

14 talent development in football. Moreover, the importance of informational support

15 provided by football brothers and football fathers have been brought to the fore; as have

16 the mechanisms by which football fathers can positively influence the talent

17 development of their daughters through the interaction of high level informational

18 support and understanding the needs of their daughter - players. Finally, we have

19 interpreted self-regulative characteristics including self-reflection as factors that can

20 potentially differentiate the rate of development of female players at youth elite level.

21 From these initial findings stem several important research and practice implications.

22 Firstly, it is important to acknowledge that the sample size, homogeneous nature of the

23 sample, and the family structure (i.e., having a father and / or brother with playing /

24 coaching experience in high level football) of the players investigated potentially limits

25 generalizability, Therefore, it would be prudent to study those young female players 
1 who do not have access or exposure to similar environmental factors and conditions.

2 Secondly, given some of the clear developmental stages and transitions that these young

3 female players experienced, there is an opportunity for research to target the demands of

4 each specific transition with greater scrutiny. For example, prospective longitudinal

5 research with players from 10-14 years old may help to understand their challenges and

6 resources in more depth (e.g., how young females cope when they are no longer able to

7 compete with boys in mixed teams; in order to inform this policy). Thirdly, by using the

8 visual progressions of the CSA and relevant quotes from participants, the content and

9 messages of educational workshops for parents, adolescent players and coaches may be

10 strengthened. Managing friendships, a disciplined and committed lifestyle, and self-

11 reflection are a few key educational themes reinforced by this research.

12 In sum, we feel that this research provides the starting point for a thoughtful

13 dialogue between scholars, practitioners, clubs and federations to inform the

14 development of female youth football players.

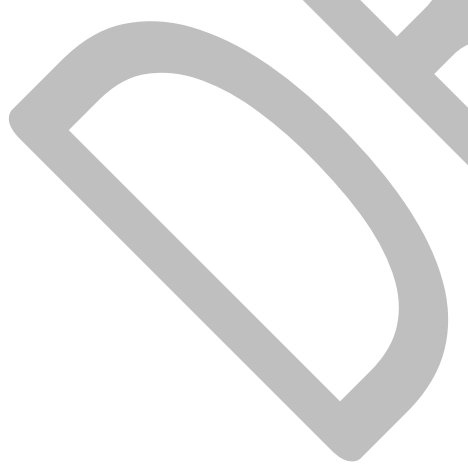




\section{References}

2 Azmitia, M.J., \& Hesser, J. (1993). Why siblings are important agents of cognitive

3 development: A comparison of siblings and peers. Child Development, 64, 430-444.

4 Bailey, R., Collins, D., Ford, R., Macnamara, A., Toms, M., \& Perce, G. (2009).

5 Participant development in sport: An academic review. Leeds: SportsCoachUK.

6 Barker, D., Barker-Ruchti, N.N., Gerber, M.M., Gerlach, E.E., Knöpfli, M.M., Sattler,

7 S.S., \& Pühse, U.U. (2010). Swiss youths and the storying of non-participation in

8 organised sport: A narrative examination of two cases. Journal of Sport Science and

$9 \quad$ Physical Education Bulletin, 60, 38-43.

10 Becker, A.J. (2009). It's not what they do, it's how they do it: Athlete experiences of

11 great coaching. International Journal of Sport Science and Coaching, 4, 93 - 119.

12 Berry, J., Abernathy, B., \& Côté, J. (2008). The contribution of structured activity and

13 deliberate play to the development of expert perceptual and decisions making skills.

14 Journal of Sport \& Exercise Psychology, 30, 685-708.

15 Bishop, D. (2008). An applied research model for the sports sciences. Sports Medicine, $38,253-263$.

17 Brockner, J., \& Higgins, E.T. (2001). Regulatory Focus Theory: Implications for the

18 study of emotions at work. Organizational Behaviour and Human Decision

19 Processes, 86, 35-66.

20 Chase, S. E. (2005). Narrative inquiry: Multiple lenses, approaches, voices. In N.K. Denzin \& Y.S. Lincoln (Eds.), The handbook of qualitative research (3rd ed., pp.651-679). Thousand Oaks, Ca.: Sage.

23 Christensen, M.K. (2009). “An eye for talent”: Talent identification and the "practical 24 sense" of top - level soccer coaches. Sociology of Sport Journal, 26, 365 - 382. 
1 Conroy, D. E., Kaye, M. P., \& Schantz, L. H. (2008).Quantitative research

2 methodology. In T. Horn (Ed.), Advances in sport psychology (3rd edn., pp. 15-30).

3 Champaign, IL: Human Kinetics.

4 Côté, J., Baker, J., \& Abernethy, B. (2003). From play to practice: A developmental

5 framework for the acquisition of expertise in team sport. In J. Starkes \& K.A.

6 Ericsson (Eds.), Expert performance in sports: Advances in research on sport

7 expertise (pp.89-110). Champaign, IL: Human Kinetics.

8 Côté, J., Baker, J., \& Abernethy, B. (2007). Practice and play in the development of

9 sport expertise. In G. Tenenbaum \& R.C. Eklund (Eds.), Handbook of Sport

10 Psychology (3rd ed., pp. 184-202). Hoboken, NJ: Wiley.

11 Côté, J., Salmela, J., Baria, A., \& Russel, S. (1993). Organizing and interpreting

12 unstructured qualitative data. The Sport Psychologist, 7, 127-137.

13 Davis, N.W., \& Meyer, B.B. (2008). When sibling becomes competitor: A qualitative

14 investigation of same-sex sibling competition in elite sport. Journal of Applied Sport

15 Psychology, 20, 220-235.

16 Douglas, K. \& Carless, D. (2008). Using stories in coach education. International

17 Journal of Sport Science and Coaching, 3, $33-49$.

18 Douglas, K. \& Carless, D. (2009). Abandoning the performance narrative: Two

19 women's stories of transition from professional sport. Journal of Applied Sport

20 Psychology, 21, $213-230$.

21 Fasting, K., \& Pfister, G. (2000). Female and male coaches in the eyes of female elite

22 football players. European Physical Education Review, 6, 91 - 110.

23 Ford, P.R., Yates, I., \& Williams, A.M. (2010). An analysis of practice activities and

24 instructional behaviours used by youth soccer coaches during practice: Exploring the

25 link between science and application. Journal of Sports Sciences, 28, $483-495$. 
1 Gershgoren, L., Tenenbaum, G., Gershgoren, A. \& Eklund, R. (2011). The effect of

2 parental feedback on young athletes' perceived motivational climate, goal

3 involvement, goal orientation, and performance. Psychology of Sport and Exercise,

$4 \quad 12,481-489$.

5 Gill, D. (2001). Feminist sport psychology: A guide for our journey. The Sport

$6 \quad$ Psychologist, 15, $363-372$.

7 Gledhill, A., \& Harwood, C. (2011, July). A systematic review of psychosocial factors associated with talent development in soccer. Paper presented at the $13^{\text {th }}$ FEPSAC

9 European Congress of Sport Psychology, Madeira.

10 Haggan, P. (2002). Family resilience through sports: The family as a team. The Journal 11 of Individual Psychology, 58, 279 - 289.

12 Hellison, D. (1995). Teaching responsibility through physical activity. Champaign, IL:

13 Human Kinetics.

14 Hellison, D., \& Walsh, D. (2002). Responsibility-based youth programs evaluation:

15 Investigating the investigations. Quest, 54, 292-307.

16 Higgins, E. T. (2000). Making a good decision: value from fit. American Psychologist, $17 \quad 55,1217-1230$.

18 Holt, N.L. (ed.) (2008). Positive Youth Development through Sport. London: Routledge.

19 Holt, N.L. \& Black, D.E. (2007). Parenting styles and specific parenting strategies in 20 youth sport. Journal of Sport \& Exercise Psychology, 29, S170.

21 Holt, N.L., Black, D.E., Tamminen, K.A., Fox, K.R., \& Mandigo, J.L. (2008). Levels of 22 social complexity and dimensions of peer experiences in youth sport. Journal of $23 \quad$ Sport and Exercise Psychology, 30, $411-431$. 
1 Holt, N.L., \& Dunn, J.G.H. (2004). Toward a grounded theory of the psychosocial

2 competencies and environmental conditions associated with football success. Journal

3 of Applied Sport Psychology, 16, $199-219$.

4 Holt, N.L., \& Mitchell, T. (2006). Talent development in English professional football. International Journal of Sport Psychology, 37, 77 - 98.

6 Holt, N.L., Tamminen, K.A., Black, D.E., Mandigo, J.L. \& Fox, K.R. (2009). Youth

7 sport parenting styles and practices. Journal of Sport and Exercise Psychology, 31, $8 \quad 37-59$

9 Holt, N.L., Tamminen, K.A., Tink, L.N. \& Black, D.E. (2009). An interpretive analysis 10 of life skills associated with sport participation. Qualitative Research in Sport and $11 \quad$ Exercise, 1, 160-175.

12 Hong, F. (2003). Football: A sport for women. Soccer and Society, 4, 268 - 270.

13 Hubball, H., and Robertson, S. (2004). Using problem - based learning to enhance team 14 and player development in youth sport. Journal of physical education, recreation $15 \quad$ and dance, $75,38-52$

16 Jonker, L., Elferenk - Gemser, M.T., \& Visscher, C. (2010). Differences in self regulatory skills among talented athletes: The significance of competitive level and type of sport. Journal of Sports Sciences, 28, $901-908$.

Jowett, S. \& Timson-Katchis, M. (2005). Social networks in sport: Parental influences on the coach-athlete relationship. The Sport Psychologist, 19, 267 - 287.

King, K.A., Tergerson, J.L. \& Wilson, B.R. (2008). Effect of social support on Activity and Health, 5, 374-384. maternal and dual-residence arrangements. Journal of family issues, 23, 672-697. 
1 Miles, M.B., \& Huberman, A.M. (1994). Qualitative data analysis: An expanded

2 sourcebook ( $2^{\text {nd }}$ ed.). Thousand Oaks, CA: Sage

3 Moran, M.M., \& Weiss, M.R. (2006). Peer leadership in sport: Links with friendship,

4 peer acceptance, psychological characteristics and athletic ability. Journal of Applied

$5 \quad$ Sport Psychology, 18, $97-113$.

6 Nieuwenhuys, A., Vos, L., Pijpstra, S., \& Bakker, F.C. (2011). Meta experiences and

7 coping effectiveness in sport. Psychology of Sport and Exercise, 12, 135 - 143.

8 Patton, M.Q. (2002). Qualitative evaluation and research methods ( ${ }^{\text {rd }}$ ed.) Newbury

9 Park, CA: Sage.

10 Pitts, M.J. \& Miller-Day, M. (2007). Upward turning points and positive rapport -

11 development across time researcher - participant relationships. Qualitative Research,

$127,177-201$.

13 Rubin, H.J., \& Rubin, I.S. (2005). Qualitative interviewing: The art of hearing data (2 ${ }^{\text {nd }}$

14 ed.) Thousand Oaks, CA: Sage.

15 Sapieja, K.M., Dunn, J.G.H., \& Holt, N.L. (2011). Perfectionism and perceptions of

16 parenting styles in male youth soccer. Journal of Sport \& Exercise Psychology, 33,

$17 \quad 20-39$.

18 Smith, B. (2010). Narrative inquiry: Ongoing conversations and questions for sport and

19 exercise psychology research. International Review of Sport and Exercise

$20 \quad$ Psychology, 3, $87-107$.

21 Sulloway, F.J. (1996). Born to Rebel: Birth Order Family Dynamics, and Creative

22 Lives. New York: Panthean Books.

23 Toering, T.T., Elferenk - Gemser, M.T., Jordet, G., \& Visscher, C. (2009). Self -

24 regulation and performance level of elite and non - elite youth football players.

$25 \quad$ Journal of Sports Sciences, 27, $1509-1517$. 
1 Thomas, W.I., \& Thomas, D. (1928). The Child in America. New York: Knopf.

2 Ullrich - French, S., \& Smith, A.L. (2006). Perceptions of relationships with parents

3 and peers in youth sport: Independent and combined prediction of motivational

4 outcomes. Psychology of Sport and Exercise, 7, $193-214$.

5 Ullrich - French, S., \& Smith, A.L. (2009). Social and motivational predictors of 6 continued youth sport participation. Psychology of Sport and Exercise, 10, 87 - 95.

$7 \quad$ Van Yperen, N.W. (2009). Why some make it and others do not: Identifying

8 psychological factors that predict career success in professional adult soccer. The

$9 \quad$ Sport Psychologist, 23, 317-329.

10 Weiss, M.R., Amorose, A.J., \& Wilko, A.M. (2009). Coaching behaviours, motivational

11 climate and psychosocial outcomes among female adolescent athletes. Paediatric

12 Exercise Sciences, 21, 475-492.

13 Wiese - Bjornstal, D.M., LaVoi, N.M., \& Omli, J. (2009). Child and adolescent

14 development and sport participation. In B.W. Brewer (Ed.), Handbook of Sports

15 Medicine and Science: Sport Psychology (pp. 97 - 112). Chichester, West Sussex:

16 Wiley - Blackwell.

17

18

19

20

21

22

23

24 


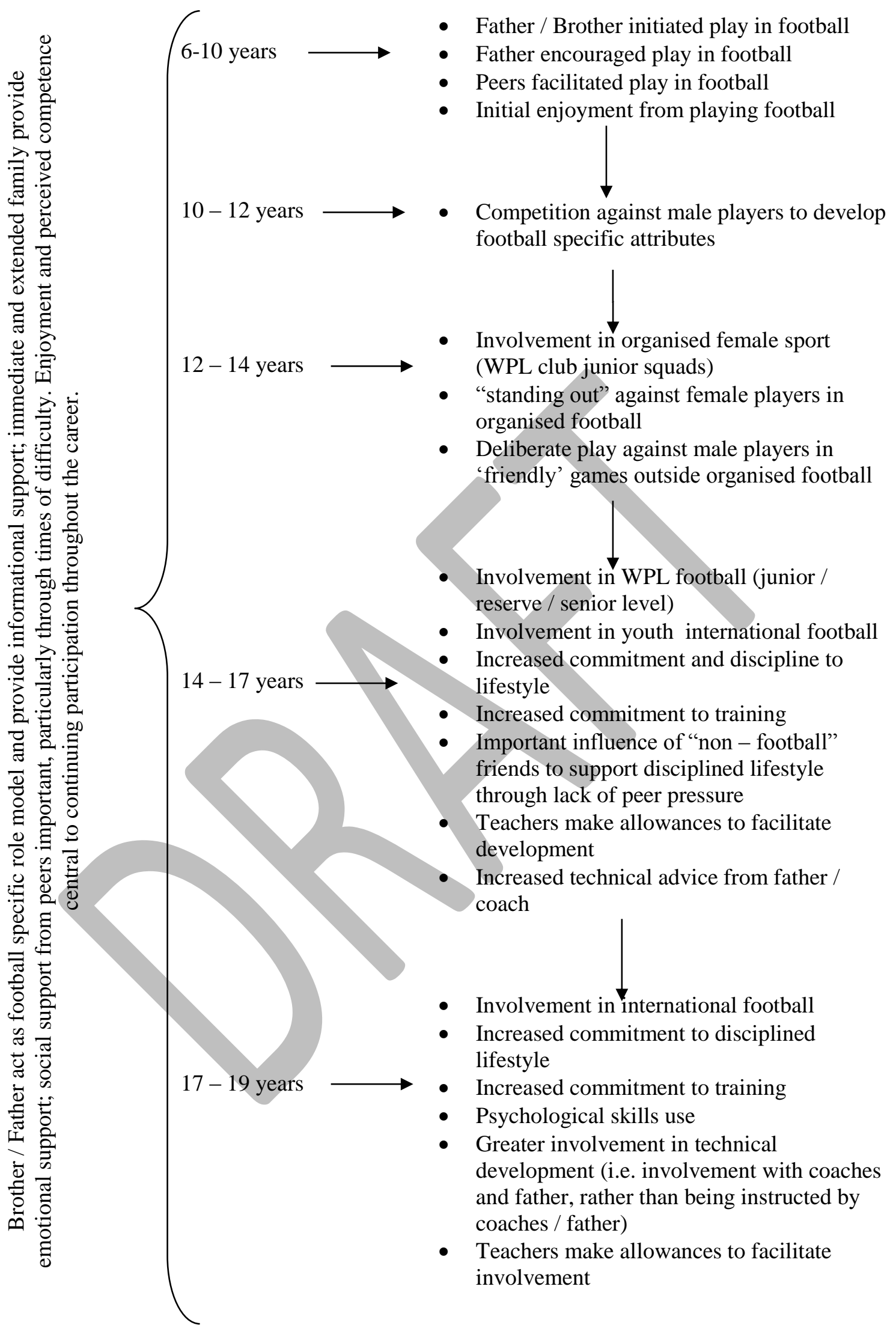

2 Figure 1. Composite Sequence Analysis of factors positively influencing the

3 development of elite female youth football players. 